\title{
Reproductive Health Services in Russia and CEE - a Review of Providers and Provider-Patient-Relations Research in English 1990-2010
}

MERI LARIVAARA, MD, M.A., Development Manager, National Institute for Health and Welfare (THL), Helsinki, Finland

\begin{abstract}
Reproductive health services within Russia and Central Eastern European (CEE) postsocialist countries received particular attention both internationally and nationally in the early 1990s. There was a shared concern about access to proper services in the field of family planning and antenatal care and about the knowledge, attitudes, and practices of medical professionals. Yet comprehensive reviews of research literature on the topic are difficult to find in English. This review was written to construct a general view of the situation in Russia and CEE countries for the purposes of a research project on reproductive health services in St. Petersburg. The review consists of empirical reports and systematic reviews published in English. It is structured in two parts: (1) providers' knowledge, attitudes and practices regarding family planning and (2) patient involvement in clinical decision-making and provider-patient relationships in reproductive health services.
\end{abstract}

Keywords: Family planning, reproductive health, health services, Russia, CEE countries

\section{Introduction}

Reproductive health services received particular attention both internationally and within Russia and Central Eastern European post-socialist countries (CEE countries) in the early 1990s after the end of socialist rule. There was a shared national and international concern about access to proper family planning, antenatal care and maternity services and about the knowledge, attitudes, and practices of medical professionals. This concern resulted in a number of development projects and some research in the 1990 as well as in the 2000s, although the international concern has faded to some extent over the years.

Despite the earlier international interest, comprehensive reviews of research literature on providers and provider-patient relations in reproductive health services in Russia and CEE countries are difficult to find in English. This review was originally written to construct a general view of the situation in Russia and CEE countries for the purposes 
of the REFER (Reproductive health and fertility - a comparative approach) research project on reproductive health services in St. Petersburg, Russia, including my own study on provider-patient relations (Larivaara 2012). Therefore research from Russia or specifically from St. Petersburg has been the starting point of the review, and studies from CEE countries have been reviewed to provide comparative perspectives from geographical areas with relative socio-historical closeness to St. Petersburg. With reproductive services I here understand health care services in the field of family planning (including contraceptive use and induced abortion services) and antenatal care. Reproductive health can broadly be defined as covering problems as "medical problems related to pregnancy, childbearing and infancy" (1996, p.1), while the more sociocultural field of sexual health involves "helping people to gain full control of their own sexuality and to enable them to accept and enjoy it to its full potential" (Ketting 1996). In the studies reviewed here reproductive health is largely related to family planning and contraception as well as to pregnancy monitoring, thus including some aspects of sexual education and sexual health (Lottes 2000).

Obviously grouping CEE countries together is in many ways problematic since the countries differ from one another in terms of culture, religion, history, ethnicity, and politics. With regard to reproductive health services, many differences were striking already under state socialism, ranging from practically free access to abortion services in Russia and several other CEE countries to the prohibition of abortion in Romania under Ceauşescu, or from the limited availability of reliable contraceptive methods in most of the CEE countries to access to Western-produced methods of birth control in Hungary. What seems to be a common feature of CEE countries is that in the postsocialist period starting from approximately the early 1990s women's reproductive rights and health issues have gained a strong symbolic meaning as the subject of political power struggles (Alsop and Hockey 2001; Gal and Kligman 2000a, 15-36, 2000b; Kliment and Cupanik 1999; Mishtal 2009).

This review concentrates on articles published in the English language and reporting empirical analysis of research material or systematic reviews that examine (1) providers' knowledge, attitude and practices towards family planning, and (2) patient involvement and provider-patient relationships in reproductive health services in urban Russia and CEE countries. Empirical reports and systematic reviews were chosen as they were expected to provide the most reliable information about the research topic.

\section{Methods}

Studies published between 1990 and 2010 in the English language were included. The literature search was originally conducted for the period between 1980 and 2010, but only three articles of potential relevance were identified from the 1980s and they were not accessible, having been published in small Eastern European medical jour- 
nals. Owing to the limited number of articles on Russia or CEE countries, books and reports were selected if they met the other inclusion criteria. To expand the literature on Russia, studies that focused on other aspects of reproductive health services but reported observations on provider-patient relationships as spin-offs were also included. Extending the literature review to studies published in Russian would have been useful, as many Russian scholars still publish mostly in Russian, but unfortunately this was not possible owing to my lack of fluency in Russian. (For the reader interested in Russian studies on the topic, two recent anthologies with qualitative research data (Zdravomyslova and Temkina 2009 and 2012) are useful sociological entries into the field of patient-provider relations.)

The literature search was conducted by using the Medline (Ovid) database (MeSH Terms). Searches were also performed on the following online databases: Academic Search Elite and SocINDEX, ERIC (CSA), and Science Direct (Elsevier). In addition, the reference lists of the reviewed articles, books, and reports were searched manually. Furthermore, articles, books and reports on Russia or CEE countries that had been identified previously through Internet or personal communications were included even if they did not appear in the literature search.

Different combinations of the following search terms were used: [family planning services OR reproductive health services OR patient / client participation / involvement OR doctor / provider / physician / professional - patient / client relationship / communication OR agency relationship OR condom OR contraception OR family planning OR hormonal contraception OR induced abortion OR intrauterine device OR oral contraceptive] AND [Russia OR Soviet Union OR USSR OR Eastern Europe OR Central Eastern Europe OR Bosnia OR Bulgaria OR Croatia OR Czech Republic OR Estonia OR Hungary OR Latvia OR Lithuania OR Poland OR Romania OR Serbia OR Slovakia OR Slovenia] They were first evaluated according to the title and then according to the abstract to decide whether they met the inclusion criteria.

Reproductive health services and provider-patient relationships are broad and valueladen topics (eg. Lottes 2000). The perspectives used in research literature vary according to time, place, and the viewpoint taken by the researcher(s). This literature review is structured in two parts according to the perspectives used in the literature search:

1. Providers' knowledge, attitudes and practices regarding family planning

2. Patient involvement in clinical decision-making and provider-patient relationships in reproductive health services

Each part will begin with a review of literature from Russia and proceed to the literature from CEE countries. Conclusions to the whole literature review will be given in a separate subchapter. The concluding part is structured around the following four questions: 
1. Which aspects of the topic have been studied?

2. What are the key results?

3. What kind of time trends can be identified in the topics of the studies and in the results?

4. What kind of gaps can be identified in the existing literature?

\section{Providers' knowledge, attitudes and practices regarding family planning}

The literature from Russia on providers' knowledge, attitudes and practices regarding family planning consists of 12 different publications based on seven different data sets (Table 1). The data were collected between the early 1990s and 2003. Only two data sets included systematic research data on health providers (Rivkin-Fish 1997, 1999, 2000, 2004, 2005; Visser, Bruyniks and Remennick 1993; Visser, Remennick and Bruyniks 1993). One more data set included interviews and observations with reproductive health providers, but this data was collected for situation analysis and was not described in detail. Thus it was impossible to estimate whether it was systematic enough for research purposes (Stephenson et al. 1997). The remaining four studies relied on second-hand data reported by patients (Client Perceptions... 1998; David et al. 2007; Kulakov, Vikhlyaeva and Nikolaeva 1997; Sherwood-Fabre, Godberg and Bodrova 2002). Only one of the data sets was collected in the 2000s (David et al. 2007). Furthermore, only one of the data sets included systematic observations of clinical work, conducted in an in-patient setting (Rivkin-Fish 1997, 2005), whereas the rest relied on self-reported (Visser et al. 1993a, 1993b) or second-hand data (Client Perceptions... 1998; David et al. 2007; Kulakov et al. 1997; Sherwood-Fabre et al. 2002), or involved less systematic observations (Stephenson et al. 1997). As a whole, the literature can be described as being heterogeneous and insufficient for drawing a systematic overview of the current knowledge, attitudes, and practices of reproductive health providers regarding family planning.

Despite its non-systematic nature, the literature is consistent in reporting three observations. First, physicians in different parts of the country had inadequate and sometimes misguided knowledge of reliable contraceptive methods in the first half of the 1990s (Stephenson et al. 1997; Visser et al. 1993a, 1993b). A survey from the early 1990s reported that less than 40 percent of gynaecologists were familiar with different mechanisms of oral contraceptives and half of them considered the rhythm method, withdrawal, vaginal douches, and the cervical mucus method as unreliable methods of contraception (Visser et al. 1993a, 1993b). The data are from the same period, making it impossible to estimate any time trends in physicians' knowledge on contraceptive methods. 
Second, providers' attempts to promote reliable use of contraception have not been sufficient in a context where unwanted pregnancies are common and knowledge of reliable contraceptive methods is low among the population (Client Perceptions... 1998; David 2007; Kulakov et al. 1997; Sherwood-Fabre et al 2002; Stephenson et al. 1997). For example, a survey carried out in 1996 in the Moscow region reported that only 36 percent of women had been counselled on contraception by their physician after a termination of pregnancy (Kulakov et al. 1997) and another study reported that in 2000 in the Novgorod and Perm regions only 40 percent of women received counselling after an induced abortion (David et al. 2007). The literature included two intervention studies that aimed at increasing the likelihood of women receiving family planning counselling. The first of them failed to achieve its goal and the post-intervention survey suggested that a number of opportunities for counselling were missed by health providers (Sherwood-Fabre et al. 2002). The latter was more successful and resulted in an impressive increase in the frequency of counselling (David et al. 2007). The ethnographic study conducted in the 1990s in St. Petersburg revealed that a small number of gynaecologists were actively engaged in educational activities to reduce the number of induced abortions, suggesting variation in the efforts of reproductive health providers to influence the current situation of family planning (Rivkin-Fish 1999, 2005, 91-119). The studies do not reveal a consistent time trend in physicians' activity in family planning counselling, although the article relying on the most recent data set of an intervention study reported a positive change after the intervention (David et al. 2007).

Third, the literature depicts overall a picture wherein health providers tend to have an authoritative and normative attitude towards family planning counselling (Client Perceptions... 1998; Rivkin-Fish 1997, 1999, 2000, 2004, 2005; Visser 1993a). In a survey from the early 1990s, 58 percent of gynaecologists reported leaving the final choice of method to the patient, but a majority of them ( 54 percent of the total sample) described their counselling style as directive. An ethnographic study of St. Petersburg examined the providers' struggle for authority over family planning and their normative attitudes towards birth control, motherhood and willingness to submit to specialist authority in reproductive health matters (Rivkin-Fish 1997, 1999, 2004, 2005). The data are from the 1990s and do not reveal any consistent time trend in physicians' attitudes.

The literature from CEE countries on providers' knowledge, attitudes and practices consist of eight different publications that are based on seven different data sets (Table 1). The data were collected between 1991 and 2006, and they are available from Estonia (Lember et al. 1999), Lithuania (Jaruseviciene and Levasseur 2006), Romania (Johnson and Horga 1993; Johnson, Horga and Andronache 1996; Johnson, Horga and Fajans 2004; Lüdicke, Horga and Campana 2001), Serbia (Sedlecky and Raševic 2008), and the former Czech and Slovak Federal Republic (Visser et al. 1993c). Six data sets included survey material or interviews with health providers (Jaruseviciene 
and Levasseur 2006; Johnson and Horga 1993; Johnson et al. 1996, 2004; Lember et al. 1999; Lüdicke et al. 2001; Sedlecky and Raševic 2008; Visser et al. 1993c), and two of them interviews with service users as well (Johnson and Horga 1993; Johnson et al. 1996, 2004). Overall, the data are sporadic and it is not possible to construct a reliable analysis of the situation in CEE countries. Romania was the only CEE country where it was possible to locate more than one study. It has probably attracted more research interest than the other countries owing to the prohibitive abortion policy under Ceauşescu and the subsequent high level of induced abortions.

The data from two Baltic countries - Estonia (Lember et al. 1999) and Lithuania (Jaruseviciene and Levasseur 2006) - were collected in the particular setting where reproductive health services were formerly provided by gynaecologists, but attempts were made to encourage general practitioners to provide them. In Estonia, more than half of the general practitioners thought that family planning should be an essential part of their work and nearly two-thirds of them felt competent in terms of family planning (Lember et al. 1999). In Lithuania, the study was confined more narrowly to the general practitioners' role in providing reproductive health services for teenagers. In qualitative interviews the general practitioners were unwilling to provide teenagers with these services and felt that they did not have enough training to do so (Jaruseviciene and Levasseur 2006).

In the former Czech and Slovak Federal Republic a survey study on gynaecologists' knowledge, attitudes and practices was performed in 1992. The gynaecologists were insufficiently informed on oral contraception, but the majority of them showed positive attitudes towards providing family planning services. Nearly two-thirds also reported that they left the final choice of contraception to the patient (Visser et al. 1993c). A similar study was conducted in Serbia nearly 15 years later (in 2006), reporting insufficient knowledge on oral contraception among gynaecologists (Sedlecky and Raševic 2008).

As noted above, Romania seems to be the best-studied among the CEE countries. A relatively large study with different methods of data collection was conducted in 1991-92. The results reveal that gynaecologists needed more information about contraceptive methods, they had positive attitudes about the use of contraception by the population and they regarded women's legal right to termination of pregnancy important. The study also reported, however, that gynaecologists felt it was not their job to educate the population about family planning (Johnson and Horga 1993; Johnson et al. 1996). Ten years later another large study was conducted in Romania. According to this study family doctors had insufficient training for providing contraceptive services, and post-abortion contraceptive counselling was deficient (Johnson et al. 2004). A third study in Romania provided a description of a training programme for gynaecologists. It reported positive results in increasing family planning training in the early 2000s (Lüdicke et al. 2001). 


\section{Patient involvement and provider-patient relationships in reproductive health services}

Patient involvement and provider-patient relationships in reproductive health services in Russia were discussed in 14 publications based on nine different data sets (Table 2). The data were collected between 1991 and the late 2000s. Seven data sets (nine publications) consisted of survey or interview data on service users (Callister et al. 2007, 2009; Chalmers et al. 1998a, 1998b; Client Perceptions... 1998; Ivanov 2000; Ivanov and Flynn 1999; Ivanov, Flynn and Martin 1995; Temkina and Zdravomyslova 2008). One data set (four publications) included clinical observations and qualitative interviews with both service users and health providers (Rivkin-Fish 1997, 2000, 2004, 2005). One more publication was based on personal experience and observations of a reproductive health service consultant and did not include systematic research data (Chalmers 1997). Only one study was conducted in an urban area other than St. Petersburg (Client Perceptions... 1998). Altogether the studies provide a comprehensive and consistent picture of service user experiences of patient involvement and providerpatient relationships in reproductive health services - albeit mostly prenatal and delivery services - in St. Petersburg. Health provider perspectives and actual observations of patient involvement remain limited, however.

User experiences of prenatal care were examined in a survey study in 1994. Slightly over half of the respondents had positive experiences of prenatal care and the physicianpatient relationship. Seeing the same physician throughout prenatal care increased the likelihood of patient satisfaction. Yet nearly half of the respondents had negative experiences, mainly owing to inconvenience related to frequency of visits and laboratory tests (Ivanov 2000; Ivanov and Flynn 1999). A baseline survey in 1995 and its follow-up in 1997 reported decreasing satisfaction in patients' experience of delivery, although hospitals had adopted family-oriented practices in between (Chalmers et al. 1998a, 1998b). Qualitative studies from the 1990s reported more problems in providerpatient relationships from the user perspective - such as being afraid, not liking to visit the physician, not liking the way they were treated, not receiving good service, lack of trust in providers, use of different informal strategies in order to secure personalised and kind treatment (Ivanov et al. 1995; Rivkin-Fish 1997, 2005).

The data from 2000s do not report any remarkable change in user experiences of reproductive health services in St. Petersburg. A qualitative study among women who had recently delivered reported that women felt having been involved in decision-making during labour and birth, but they expected more advice and support from medical and midwifery personnel (Callister et al. 2007). Participants in another study experienced reproductive health services as uncomfortable mainly owing to the way in which patients were treated by medical and nursing personnel and because they were unable to trust health providers. They felt that private services were more reliable and better 
organised than public ones and that their physical, emotional, and social demands were more likely to be met by private services. The use of different informal strategies to secure reliable and kind treatment continued to be widespread (Temkina and Zdravomyslova 2008). An evaluation of the treatment at the Women's Wellness Centre in St. Petersburg - a special clinic with supposedly a more patient-centred approach to services - reported different kinds of results: service users found the care comprehensive and attentive and the personnel positive and caring (Callister et al. 2009).

An ethnographic study conducted in the 1990s in St. Petersburg suggests that reproductive health providers had an authoritative attitude towards their patients and commonly felt frustration towards their patients' living habits and attitude towards their health. Yet the study also reveals that physicians valued warm and personal provider-patient relationships (Rivkin-Fish 1997, 2000, 2005). Observations conducted in the same period reported that clinical interactions were hierarchical, care was expert-centred and technically-oriented, and health providers showed little concern for patients' psychosocial and emotional needs and privacy (Chalmers 1997; Rivkin-Fish 1997, 2005). However, the picture is mixed, and a small number of health activists were engaged in educating providers to become more sensitive to patient needs and wishes during clinical encounters (Rivkin-Fish 2004).

The literature from CEE countries on patient involvement and provider-patient relationships in reproductive health services is scarce. Eight different publications were identified and they were based on seven different data sets (Table 2.) The data extend from 1991 to the 2000s. There are research publications available from Bulgaria (Todorova et al. 2006), Hungary (Scanlan et al. 1996), Lithuania (Jaruseviciene, Levasseur and Liljestrand 2006; Lazarus, Jaruseviciene and Liljestrand 2008), and Romania (Johnson and Horga 1993; Johnson et al. 1996, 2004; Todorova et al. 2006). One data set is based on a survey on service users (Scanlan et al. 1996), three on survey and interview data on health providers (Jaruseviciene et al. 2006; Lazarus et al. 2008; Todorova et al. 2006), and two include data on both service users and health providers. In addition, a book chapter was based on personal experience and observations of a reproductive health service consultant in Estonia, Czech Republic, Hungary, Latvia, Poland, and Romania (Chalmers 1997). The data are not systematic and do not allow a trustworthy analysis of the situation in CEE countries. Romania is the exception, with three different studies conducted in the country (Johnson and Horga 1993; Johnson et al. 1996, 2004; Todorova et al. 2006).

Chalmers (1997) reported her personal experiences and observations as a reproductive health service consultant in Estonia, the Czech Republic, Hungary, Latvia, Poland, and Romania between 1991 and 1997. According to her, maternity care was technicallyoriented and expert-centred throughout the area, and health providers tended to neglect women's psycho-social and emotional needs (Chalmers 1997). A survey of service users 
that was conducted in Hungary before 1996 reported that slightly more than half of the respondents were satisfied with the healthcare personnel and the care received, and almost one-fifth was not satisfied with the personnel and nearly a quarter dissatisfied with the care. The reasons for dissatisfaction were inappropriate behaviour towards patients, long waiting times, and lack of hygiene (Scanlan et al. 1996). With regard to the providers' perspective, semi-structured interviews in Romania and Bulgaria revealed several discourses on women's responsibility over their own health in relation to cervical cancer screening, some of the discourses being normative whereas others saw women as victims of healthcare reforms (Todorova et al. 2006). The two studies from Lithuania focused on providers' attitudes to confidentiality of adolescents' reproductive health care (Jaruseviciene et al. 2006; Lazarus et al. 2008).

Regarding Romania, studies have focused on induced abortion services and contraceptive counselling. One study reports that women expect gentle and supportive behaviour from providers in induced abortion services. Giving gifts to physicians in abortion services is common and almost one-third of the female respondents expected to do that to improve treatment, whereas nearly 40 percent thought the opposite. Women expect their gynaecologist to initiate conversation about contraception, which is recognised by nearly 70 percent of the providers (Johnson and Horga 1993; Johnson et al. 1996). Yet according to another study physicians provided little information to women about termination of pregnancy or contraception (Johnson et al. 2004). Furthermore, normative attitudes towards women are not unusual among reproductive health providers in Romania (Johnson and Horga 1994; Johnson et al. 1996, 2004; Todorova et al. 2006).

\section{Conclusions}

The literature review revealed that publications on providers' knowledge, attitude and practices towards family planning, as well as on patient involvement and providerpatient relationships in reproductive health services in urban Russia and the Central Eastern European post-socialist countries are scarce - at least in the English language. The quality of publications varies from peer-reviewed high-quality articles to working papers and descriptions of personal experiences. Different research methods have been applied both in Russia and in CEE countries, ranging from provider and user surveys to qualitative interviews, observations, and ethnography. The data are sporadic and cannot provide a comprehensive picture of the situation in the countries examined. Direct observations in particular are scarce, and conclusions are commonly drawn on the basis of second-hand or self-reported data.

Certain general observations can be made on the basis of the literature review, however. As regards providers' knowledge, attitudes and practices in Russia, researchers were clearly quite interested in the level of knowledge among service providers in the field of family planning in the early 1990s, but these early results were not followed up in 
later research. By contrast provider counselling activity continued to interest researchers during the decades covered in this review. The data are consistent in reporting low levels of counselling activity in the 1990s, but it is difficult to estimate the situation in the 2000s. Studies also consistently describe an authoritative, directive and normative counselling style among providers, but data are not available from the early $2000 \mathrm{~s}$ onwards. As regards CEE countries, the data are too scattered and sometimes too context-bound to allow for reliable analysis of any trends.

When it comes to patient involvement and provider-patient relationships, user experiences from prenatal and delivery services in St. Petersburg are reported in a relatively large number of studies. It seems that qualitative methods detect more problems than survey methods from the user perspective. Nevertheless, it can be concluded that patients are less than satisfied with the way they are treated in prenatal and delivery services in St. Petersburg. Observations and studies on provider perspective are scarce, but they support the general picture reported in user studies, suggesting that providerpatient relationships are problematic in terms of authority, trust, patientcentredness, and patient involvement. Again, the studies from CEE countries are too few and spread over too large a number of countries to allow any definite conclusions to be drawn. Yet the topics chosen by researchers suggest that they are worried about problems such as confidentiality, counselling activity, patient involvement, and sensitivity to patients' needs.

When we look at the literature review, it is clear that a provider perspective is underrepresented in Russian literature, whereas data on user perspective in prenatal and delivery services in St. Petersburg are fairly comprehensive. Furthermore, data on user perspectives on contraceptive counselling and induced abortion services are limited in St. Petersburg. There are fewer data from other parts of urban Russia - not to mention the rural areas - and little attention is given to the generalisability of St. Petersburg studies to other parts of the country. Direct observations of patient involvement and provider-patient relationships are absent, with the exception of a single ethnographic study. The literature on CEE countries provides few references for comparison, as the data are even more scarce and random. Finally, a common feature of many publications on Russia and CEE countries is a critical perspective that seems to imply that researchers expect something to be wrong in terms of providers' knowledge, attitudes, practices, patient involvement, or power balance between the provider and the patient in clinical interactions. 


\section{References}

Alsop, R. and J. Hockey. 2001. Women's reproductive lives as a symbolic resource in Central and Eastern Europe. European Journal of Women's Studies 8(4): 454-471.

Callister, L. C., N. Getmanenko, N. Gavrish, O. E. Marakova, N. V. Zotina, J. Lassetter and N. Turkina. 2007. Giving birth. The voices of Russian women. MCN: The American Journal of Maternal Child Nursing 32(1): 18-24.

Callister, L. C., N. Getmanenko, N. Gavrish, O. E. Marakova, N. V. Zotina and N. Turkina. 2009. Outcomes evaluation of St. Petersburg Russia Women's Wellness Center. Health Care for Women International 30: 235-248.

Chalmers, B. 1997. Changing childbirth in Eastern Europe. Which systems of authoritative knowledge should prevail. In: Childbirth and Authoritative Knowledge. Cross-cultural Perspectives, edited by R. E. Davis-Floyd and C. F. Sargent, pp. 263-283. Berkeley: University of California Press.

Chalmers, B., M. F. Samarskaya, E. Tkatchenko and T. Wallington. 1998. Women's experiences of birth in St. Petersburg, Russian Federation. Journal of Reproductive \& Infant Psychology 16(4): 243-258. (Chalmers et al. 1998a)

Chalmers, B, H. Muggah, M. F. Samarskaya and E. Tkatchenko. 1998. Women's experiences of birth in St. Petersburg, Russian Federation. Following a maternal and child health intervention program. BIRTH 25(2): 107-116. (Chalmers et al. 1998b)

Client Perceptions of Reproductive Health Services in Vladivostok and Novosibirsk, Russia [online]. 1998. Working paper. Novosibirsk Oblast, Russia: Department of Public Health and Department of Health Services, Russia. [cited 27 march 2012]. Available from: http://www.jsi.com/JSIInternet/Resources/Publications/ familyplanning.cfm.

David, P. H., L. Reichenbach, I. Savelieva, N. Vartapetova and R. Potemkina. 2007. Women's reproductive health need in Russia. What can we learn from an intervention to improve post-abortion care? Health Policy and Planning 22: 83-94.

Gal, S. and G. Kligman. 2000a. The Politics of Gender after Socialism. Princeton: Princeton University Press.

Gal, S. and G. Kligman (eds). 2000b. Reproducing Gender. Politics, Publics, and Everyday Life after Socialism. Princeton: Princeton University Press, Princeton.

Ivanov, L. L. 2000. Use of a western theoretical model to investigate the relationships among characteristics of pregnant women, utilization, and satisfaction with prenatal care services in St. Petersburg, Russia. Public Health Nursing 17(2): 111-120.

Ivanov, L. L. and B. C. Flynn. 1999. Utilization and satisfaction with prenatal care services. Western Journal of Nursing Research 21(3): 372-386.

Ivanov, D. L., B. C. Flynn and J. B. Martin. 1995. Characteristics of pregnant women, utilization, and satisfaction with prenatal services in St. Petersburg, Russia. Public Health Nursing 12(6): 374-377.

Jaruseviciene, L. and G. Levasseur. 2006. The appropriateness of gatekeeping in the provision of reproductive health care for adolescents in Lithuania. The general practice perspective. BMC Family Practice 7: 16. 
Jaruseviciene, L., G. Levasseur and J. Liljestrand. 2006. Confidentiality for adolescents seeking reproductive health care in Lithuania. The perceptions of general practitioners. Reproductive Health Matters 14(27): 129-137.

Johnson, B. R. and M. Horga. 1993. Contraception and abortion in Romania. Lancet 341(8849): 875-878.

Johnson, B. R., M. Horga and L. Andronache. 1996. Women's perspectives on abortion in Romania. Social Science \& Medicine 42(4): 521-530.

Johnson, B. R., M. Horga and P. Fajans. 2004. A strategic assessment of abortion and contraception in Romania. Reproductive Health Matters 12(24 suppl.): 184-194.

Ketting, Evert. 1996. Sexual Health is Something Different. Choices 25, No. $2,1$.

Kliment, M. and V. Cupanik. 1999. Retaining the abortion law in Slovakia. Medicine \& Law 18(2-3): 363-371.

Kulakov, V., E. Vikhlyaeva and E. Nikolaeva. 1997. The Epidemiology of Induced Abortions in Russia. Pilot trial [online]. Copenhagen: WHO Regional Office for Europe, Copenhagen. [cited 27 March 2012]. Available from: http://whqlibdoc. who.int/euro/1994-97/EUR RUS FMLY 0423 04.pdf.

Lazarus, J., L. Jaruseviciene and J. Liljestrand. 2008. Lithuanian general practitioners' knowledge of confidentiality laws in adolescent sexual and reproductive health care. A cross-sectional study. Scandinavian Journal of Public Health 36(3): 303-309.

Lember, M., H. Sarapuu, A. Pikk and R. Kalda. 1999. Family planning and family doctors in Estonia. Scandinavian Journal of Public Health 27: 235-236.

Lottes, Ilsa. 2000. New views on sexual health. Helsinki: Population Research Institute.

Lüdicke, J. F., M. Horga and A. Campana. 2001. Reproductive health in Eastern Europe. A collaborative training project in Romania. American Journal of Public Health 91(11): 1761-1763.

Mishtal, J. Z. 2009. Matters of "conscience." The politics of reproductive healthcare in Poland. Medical Anthropology Quarterly 23(2): 161-183.

Rivkin-Fish, M. 1997. Reproducing Russia. Women's Health and Moral Education in the Construction of a Post-Soviet Society. Ph.D. dissertation. Princeton: University of Princeton, Department of Anthropology.

. 1999. Sexuality education in Russia. Defining pleasure and danger for a fledgling democratic society. Social Science \& Medicine 49(6): 801-814.

. 2000. Health development meets the end of state socialism. Visions of democratization, women's health, and social well-being for contemporary Russia. Culture, Medicine and Psychiatry 24(1): 75-98.

.2004. "Change yourself and the whole world will become kinder." Russian activists for reproductive health and the limits of claims making for women. Medical Anthropology Quarterly 18(3): 281-304.

. 2005. Women's Health in Post-Soviet Russia. The Politics of Intervention. Bloomington: Indiana University Press.

Scanlan, K. A., H. Watkins, V. de Back and C. M. May. 1996. The underuse of women's health care services in Hungary. A preliminary study. Journal of Nurse-Midwifery 41(3): 251-258. 
Sedlecky, K. and M. Raševic. 2008. Are Serbian gynaecologists in line with modern family planning? European Journal of Contraception and Reproductive Health Care 13(2): 158-163.

Sherwood-Fabre, L., H. Godberg and V. Bodrova. 2002. The impact of an integrated family planning program in Russia. Evaluation Review 26(2): 190-212.

Stephenson, P., B. Chalmers, V. F. Kirichenko, M. A. Repina and M. Wagner. 1997. Reducing maternal mortality in St. Petersburg. World Health Forum 18: 189-193.

Temkina, A. and E. Zdravomyslova. 2008. Patients in contemporary Russian reproductive health care institutions. Strategies of establishing trust. Demokratizatsiya 16: $277-293$.

Todorova, I. L. G., A. Baban, D. Balabanova, Y. Panayotova and J. Bradley. 2006. Providers' constructions of the role of women in cervical cancer screening in Bulgaria and Romania. Social Science \& Medicine 63:776-787.

Visser, A. P., N. Bruyniks and L. Remennick. 1993a. Family planning in Russia. Experience and attitudes of gynecologists. Advances in Contraception 9: 93-104.

Visser, A. P., L. Remennick L and N. Bruyniks. 1993b. Contraception in Russia. Attitude, knowledge and practice of doctors. Planned Parenthood in Europe 22(2): 26-9.

Visser, A. P., R. Uzel, E. Ketting, N. Bruyniks and B. J. Oddens. 1993c. Attitudes of Czech and Slovak gynaecologists toward family planning. Advances in Contraception 9: 351-362.

Zdravmoyslova, E. and A. Temkina (eds.). 2012. Zdorov'e i intimnaia zhizn': Sotsiologicheskie podhody. (Health and intimate life: Sociological approaches). St. Petersburg: European University at St. Petersburg Press.

Zdravmoyslova, E. and A. Temkina (eds). 2009. Zdorovie i doverie: genderniy podhod $\mathrm{k}$ reproductivnoy meditsine. (Health and Trust: Gender Approach to Reproductive Health Care.) St. Petersburg: European University at St. Petersburg Press. 